\title{
HISTORIOGRAFIAS E HISTORIOFOTIAS DA PAISAGEM
}

Resumo: O artigo em questão parte do pressuposto que a descrição da paisagem bem como o acesso a esta descrição referem-se sempre ao passado. A partir deste pressuposto, defende um aprofundamento na pesquisa interdisciplinar da paisagem, agregando à geografia elementos da teoria da história, como um meio de conceber as historiografias e as historiofotias, bem como suas limitações. O objetivo deste artigo é analisar as possibilidades e limitações dessas técnicas, em uma abordagem interdisciplinar entre a geografia, a história e a literatura.

Palavras-chave: Paisagem. Historiografias. Historiofotias.

\section{LANDSCAPE HISTORIOGRAPHIES AND HISTORIOPHOTIES}

Abstract: This article assumes that the description of the landscape as well as access to it always refer to the past. Based on this assumption, this article defends a deepening of interdisciplinary landscape research, adding elements of the theory of history to geography, as a means of conceiving historiographies and historiographies, as well as their limitations. The aim of this article is to analyze the possibilities and limitations of these techniques, in an interdisciplinary approach between geography, history and literature.

Key words: Landscape. Historiographies. Historiophoties.

\section{HISTORIOGRAFÍAS E HISTORIOFOTÍAS DEL PAISAJE}

Resumen: El artículo supone que la descripción del paisaje, así como el acceso a esta descripción, siempre se refieren al pasado. Basado en esta suposición, defiende una profundización de la investigación interdisciplinaria del paisaje, agregando elementos de la teoría de la historia a la geografía, como un medio para concebir historiografías e historiografías, así como sus limitaciones. El objetivo de este artículo es analizar las posibilidades y limitaciones de estas técnicas, en un enfoque interdisciplinario entre geografía, historia y literatura.

Palabras-Clave: Paisaje. Historiografías. Historiofotías.

\section{Introdução}

Este artigo, de cunho epistemológico, visa analisar as possibilidades e as limitações das historiografias e das historiofotias como meios de descrição da

\footnotetext{
1 Instituto Federal de Ciência e Tecnologia do Norte de Minas Gerais - Campus Salinas, Departamento de Ensino, Salinas-MG, Brasil, leonardo.silveira@ifnmg.edu.br, https://orcid.org/myorcid?orcid=0000-0002-7082-529X
} 
paisagem. A categoria geográfica em questão é extremamente sensível ao tempo atomístico inexorável bem como à intermediação das narrativas e representações imagéticas oferecidas pela intersubjetividade perceptiva do homem. Esta é a razão para nos apoiar na interdisciplinaridade que abraça o tempo-espaço como dimensões complementares, conditio sine qua non para a descrição da paisagem como uma narrativa histórica, pois esta, ao ser acessada, sempre fará referência ao tempo ido.

Aprioristicamente há de se problematizar a paisagem, que construiu diacronicamente um universo semântico extremamente plural, dando forma à sua polissemia. Resgatando os primórdios das problematizações espaciais, é plausível considerar que a sociedade humana possui um ambiente, que é percebido, expresso simbolicamente e adaptado aos seus propósitos. Entretanto, existem poucas civilizações as quais o ambiente tornou-se explícito objeto imagético-paisagístico. De fato, somente duas civilizações na história da humanidade que desenvolveram a estética da paisagem em sua plenitude: a chinesa e a europeia. Devemos, contudo, considerar ainda as respectivas esferas de influência dessas civilizações (BERQUE, 1993). Para conceber essa ideia de Augustin Berque, se faz necessária uma crucial distinção: paisagem não é o mesmo que ambiente, ${ }^{2}$ pois a compreensão e abordagem paisagística exige a transcendência da objetividade. Para Berque, o ambiente é o aspecto objetivo do meio: ou seja, "aquilo que é objetivo das relações estabelecidas entre a sociedade, o espaço e a natureza. A paisagem é a parte sensível dessas relações. Deste modo, repousa em uma forma coletiva de subjetividade" (BERQUE, 1993, p.33).

A noção de paisagem está presente na memória do ser humano antes mesmo da elaboração do conceito (MAXIMIANO, 2004). No mundo ocidental, a pintura de paisagem surgiu antes mesmo do que a própria palavra paisagem e sua problematização. Durante a Antiguidade Clássica, os estudos que incorporavam a paisagem - sem que o termo ainda tivesse sido cunhado - faziam-se presentes com a descrição dos lugares (OLIVEIRA, 2000). Na Europa, a paisagem enquanto conceito parece ser uma invenção do Renascimento (MARANDOLA; OLIVEIRA, 2018), precisamente no final do século XV e início do XVI (COSGROVE, 1985), em um momento no qual o homem passou a ser visto como uma entidade à parte da

2 O texto em inglês traz: "Landscape is not the environment" (BERQUE, 1993, p.33). A problematização de Augustin Berque já anuncia uma reflexão cujo ponto de partida distingue a noção de paisagem reificada, objetivável, de uma noção de apelo fenomenológico. 
natureza. Claude Raffestin (1977) assegura que a paisagem não era objeto de interesse dos ocidentais até a aurora do século XVI. É a necessidade de representação do Renascimento que ajuda a fundar a paisagem em um contexto que propõe a dicotomia entre o homem como sujeito e a natureza como objeto.

A paisagem era considerada como parte integrante da pintura ao ser definida como o fundo de quadros religiosos (KIYOTANI, 2014), em um momento em que o foco era o antropocentrismo, sendo representada como detalhe ou complemento das telas. A paisagem renascentista que explorava as interferências humanas na paisagem exploravam vilas ricas e poderosas, palácios e castelos, de tal modo que pouca atenção era dada à representação de paisagens ordinárias (ANTROP, 2005).

A ciência moderna, que emergiu no período da Renascença e do lluminismo, trouxe consigo a promessa de que isolando a natureza como um objeto de estudo, seria possível transformá-la e controla-la em prol do benefício da sociedade (OLWIG, 2008). A natureza, assim, transforma-se em uma construção cultural quando funções são atribuídas a ela (LARSEN, 1992). A ideia da acumulação da produção advinda do trabalho, que é uma especificidade humana bastante problematizada no século XIX, ajuda a aprofundar a separação entre homem e natureza (BURGESS, 1978). Pensando deste modo, a própria consolidação do capitalismo contribui para a cisão aqui abordada.

Os distintos entendimentos acerca da congruência entre o homem e a natureza auxiliam-nos a compreender a grande diversidade que existe entre as abordagens sobre a paisagem. Consideramos na reflexão deste artigo uma abordagem que vê na dialética entre mente e matéria (INGOLD, 1993) e subjetividade e objetividade o caminho ideal para a interpretação da paisagem, tal como preconiza Augustin Berque ao falar em geogramas e trajetividade (BERQUE, 2012; 2017). Para além dessas dialéticas que apresentamos, há a necessidade de problematizar o tempo como elemento de interpretação paisagístico.

Mostrando a consideração com tempo, Santos em sua icônica obra $A$ Natureza do Espaço conceitua: "A paisagem é o conjunto de formas que, num dado momento, exprime as heranças que representam as sucessivas relações localizadas entre o homem e a natureza" (SANTOS, 2012, p.103). Doreen Massey (2006), refletindo a paisagem na dimensão de sua efemeridade, preferiu concebê-la como eventos ou acontecimentos. Se uma dada porção do espaço constantemente se modifica, não é a mesma paisagem que podemos observar de uma janela de uma 
moradia construída em topografia privilegiada. Estaríamos falando sobre paisagens, no plural. Santos (2012) salienta que a paisagem é "história congelada", mas que participa da "história viva". Seria história congelada porque se constitui como uma fotografia captada em um dado momento do tempo. Participaria da história viva porque as suas formas realizariam, no espaço, as funções sociais. São estas funções sociais e a dinâmica da natureza que garantem a efemeridade da paisagem. Barbara Bender prefere se referir à paisagem como um tempo em materialização: assim como o tempo, a paisagem está em constante movimento (BENDER, 2002), inexorável no seu dinamismo.

É importante ressaltar que o tempo pode ser entendido de diferentes formas: de um lado, o tempo atomístico, composto por instantes e medido pelos segundos, minutos e demais padrões de medida; de outro, o tempo como movimento ou fluxo, que é socialmente construído e pode comprimir as distâncias por intermédio do aumento da velocidade. ${ }^{3}$ Este tempo socialmente arquitetado se apoia também na sazonalidade da paisagem e ajuda a construir os ciclos de trabalho. A construção do calendário e as compartimentações sociais do tempo edificam-se, dentre outras coisas, como pilares da governança (MUNN, 1992) e podem representar temporalidades assimétricas (OHNUKI-TIERNEY, 1969; FRIEDMAN, 1985). É plausível considerar que o tempo atomístico atua como um fator indireto no arranjo da paisagem (pois a sua existência permite a atuação de outros fatores), enquanto que o tempo socialmente construído atua desde as formas mais indiretas às mais diretas.

Richard $H$. Schein argumenta que a paisagem não pode ser vista simplesmente como a "soma total da história", pois o processo de leitura de paisagem deve estar "aberto ao desafio da agregação de novas informações e de interpretações alternativas" (SCHEIN, 1997, p.376). Em uma concepção mais rigorosa, a descrição da paisagem parece estar fadada a referir-se sempre aos tempos idos. Esta é a razão para acreditarmos que as historiografias e a historiofotias precisam de uma maior problematização no campo da interpretação paisagística. O nosso objetivo neste artigo, que é o de analisar as possibilidades e limitações dessas técnicas, se dará a partir da seguinte organização: primeiramente, abordaremos a paisagem como texto; segundo, problematizaremos a historiografia

3 Para aprofundar, ver a compressão espaço-temporal de David Harvey (2004) e as relações entre velocidade e política que nos traz a noção de cronopolítica (VIRILIO, 2007). 
como técnica de relato histórico, destacando os desafios e as possibilidades do seu uso na interpretação da paisagem; faremos em seguida o mesmo com as historiofotias e, por fim, traremos as considerações finais.

\section{Paisagem como texto}

Como um relato do tempo ido, não raramente é sugerida à paisagem ser vista como um texto a ser lido, que nos contaria sobre a história da própria natureza e do homem, bem como de suas relações, em escalas temporais diversas. ${ }^{4}$ A metáfora da paisagem como texto, é relativamente comum dentre os geógrafos culturais (ROWNTREE, 1986; COSGROVE; JACKSON, 1987; DUNCAN; DUNCAN, 1988). ${ }^{5}$

A chamada nova geografia cultural revitalizou a ênfase da paisagem enquanto construção cultural que estrutura e dá significado ao mundo externo. Essas simbólicas características da paisagem produzem e sustentam um sentido social. Nesse sentido a paisagem é concebida como uma configuração de símbolos e signos, fato que fortalece metodologias que são mais interpretativas do que morfológicas. Eis a explicação para a ênfase dada na metáfora da paisagem enquanto texto (ROWNTREE, 1988). Demeritt (1994) avalia que a maioria das abordagens que utiliza a metáfora da paisagem como texto negligencia a participação de atores naturais no arranjo paisagístico. Essa questão talvez se explique pela distinta temporalidade envolvendo as forças da natureza - que também possuem ritmos diferentes entre si - e as forças antrópicas. Não é incomum descrições paisagísticas que eternizam a natureza, como se os arranjos naturais não tivessem história.

O contexto da efervescência da metáfora da paisagem-texto se deu no interior da chamada virada cultural, movimento interdisciplinar que floresceu nos anos 197080 como uma reação ao pragmatismo neopositivista (MIKESELL, 1978; VALENTINE, 2001; PEDROSA, 2016). No interior da chamada virada cultural, falouse de um movimento mais específico chamado de virada linguística, que se centrou nos discursos, na representação social e na cultura política, com impactos notáveis

\footnotetext{
4 Meredith (1985) utiliza a expressão "biografia da paisagem" para se remeter ao processo de evolução da mesma. A noção de uma biografia da paisagem "comporta as vontades individuais do povo que fez escolhas durante o processo de evolução da paisagem" o que explicaria o seu arranjo contemporâneo. "Indivíduos não podem operar fora dos ambientes socioeconômicos e físicos, mas podem mediar as interações entre ambos. Essa habilidade cria a biografia das paisagens" (MEREDITH, 1985, p.46).

$5 \mathrm{Em}$ certas abordagens antropológicas, o conceito de cultura também é tratado metaforicamente como um texto (NAME, 2010).
} 
nas ciências humanas (BURGESS, 1996). Todavia, Demeritt (2002) alerta que existem várias viradas linguísticas, baseadas em abordagens relevantes de distintos autores. Comumente, quando se associa a virada linguística à virada cultural, é destacada a consolidação e disseminação do pós-estruturalismo, que fundamenta a desconstrução que tem como grande divulgador Jacques Derrida.

As metáforas como a da paisagem como texto podem fazer com que geógrafos entusiastas de abordagens materialistas e pragmáticas fiquem desconfortáveis. Contudo, lidamos constantemente com materialidades e imaterialidades, de tal forma que automatizamos os seus antagonismos. Muehrcke e Muehrcke (1974), por exemplo, assim falam acerca do mapa, um instrumental indispensável na vida de um geógrafo: “Um mapa é, de fato, uma metáfora. O criador do mapa tem a pretensão de fazer com que o leitor do mapa acredite que um mosaico de pontos, linhas e áreas em um pedaço de papel seja equivalente ao mundo multidimensional” (MUEHRCKE; MUEHRCKE, 1974, p.319).

É importante observar que os textos não são inocentes; são janelas pelas quais a realidade pode ser vista de uma forma problemática, parcial e fraturada. Como dito, a complexidade da leitura da paisagem e sua metáfora como texto encontra abrigo dentro da dimensão pós-estruturalista, que se preocupa com os significados das palavras, expressões e ideias. No interior dessa perspectiva, nenhum texto é puro, nascido livre de influências de outros textos. Por isso, é construído o axioma: todo texto é intertexto de outro texto (DUNCAN; DUNCAN, 1988). Premissas pós-estruturalistas

negam a autoria ao autor. Rejeitando a visão de que os textos são referenciais, também rejeitam a ideia de que textos são representações ou reconstruções do mundo real. Essas descrições combinam com as paisagens, pois estas não possuem autoria, embora possam ser simbólicas, não são obviamente referenciais, constituindo como criações intertextuais do leitor, assim como são produtos da sociedade que originalmente as construiu (DUNCAN; DUNCAN, 1988, p.120).

A paisagem pode ser analogamente ligada a um hipertexto em pelo menos dois âmbitos: no primeiro, em função dos valores que são carregados pelo seu intérprete, que são construídos "intertextualmente" devido às experiências múltiplas 
acumuladas espaço-temporalmente; ${ }^{6}$ no segundo âmbito, em função dos diversos processos que moldam e dão forma ao arranjo paisagístico.

Ao serem interpretados, de múltiplas maneiras, os textos da paisagem permitem a formulação de imagens que - a partir da visão de mundo do intérprete são construídas representações sobre um dado aspecto da realidade (CORRÊA, 2011). Essas representações tornam-se informações necessárias para o desempenho do importante papel da intermediação da realidade, no qual o intelectual deve abandonar a pretensão de dimensionar o real ou a verdade histórica, incorporando fragmentos ou ângulos que, se por um lado evidenciam as incompletudes de um todo objetivo, por outro nos capacitam a interagir com o espetacular multiverso da dicotomia homem versus meio.

É importante destacar que paisagem nunca é responsável por si mesma. Ela é transformada em processos que não são visíveis em sua escala de contemplação, replicando processos de origens externa, da mesma forma que os textos replicam ideias advindas de outros textos. James Duncan (1995) apontou que a fraqueza da metáfora intertextual reside no fato de que em muitas instâncias, as complexas conexões intertextuais são imensamente difíceis de serem dimensionadas ou percebidas (DUNCAN, 1995). ${ }^{7}$ Não entendemos isto como fraqueza. A pretensão de dimensionar o universo das conexões intertextuais é utópica tanto na dimensão literal da intertextualidade quanto na dimensão metafórica da paisagem como texto. De maneira semelhante, as narrativas históricas alternativas às grandes narrativas (metanarrativas) não podem se posicionar como detentoras da verdade. Grosseiramente, é razoável asseverar que é quixotesca a batalha a favor do dimensionamento da realidade, do esgotamento das narrativas e do estabelecimento da verdade. As virtudes intertextuais se apresentam justamente na possibilidade de buscar as múltiplas conexões textuais que enriquecem nossa compreensão, de forma similar ao nobre exercício de intermediação de narrativas que ajudam a enriquecer a abordagem histórica.

A metáfora da paisagem enquanto texto, para alguns, precisa ser aplicada, vista, desenvolvida e teorizada com parcimônia. Don Mitchell (1993) em uma

6 A paisagem como portadora de hipertextos permitiria a leitura de tempos pretéritos por meio de iconografias representativas de tais tempos (CARVALHO, 2017). É como consultar uma arquitetura que caiu em desuso e compreender as razões de sua obsolescência.

7 Apesar do apontamento sobre a fraqueza da intertextualidade, James Duncan é um dos grandes divulgadores da metáfora da paisagem como texto, imortalizada no seu livro The city as a text:The Politics of Landscape Interpretation in the Kandya Kingdom (DUNCAN,1990). 
resenha crítica do livro de Barnes e Duncan (1992) argumentou que a utilização da metáfora textual fez com que os autores construíssem uma argumentação que desenhavam duas possibilidades paralelas e antagônicas da interpretação paisagística: de um lado, a interpretação meramente material, a bruta realidade; de outro, o mundo dos textos, discurso, metáfora e da linguagem. Mitchell salienta que esta é uma falha grave na teoria, pois, trata-se de uma "posição frustrante, pois, o que precisa ser teorizado são as complexas interações entre a materialidade e ideias. Palavras e discursos são amarrados ao mundo por poderosos atores sociais" (MITCHELL, 1993, p.474).

Walton (1995) discordou da crítica de Mitchell em uma publicação no periódico Professional Geographer, ao argumentar que a utilização da metáfora da paisagem como texto não implica necessariamente em uma ontologia idealista (WALTON, 1995, p.62). Em tréplica à Walton (1995), Mitchell (1996) revigorou suas considerações sobre o uso da metáfora textual da paisagem, ao dizer que a capacidade dessa metáfora em suprimir a dicotomia entre ideias e materialidade não é meritória. Mitchell chama a atenção para o seguinte artifício linguístico: "A paisagem é parcialmente um texto ou uma representação. Em muitos estudos ocorre uma rápida derrapagem da noção da paisagem que se assemelha a um texto rumo à paisagem vista como um texto" (MITCHELL, 1996, p.95). ${ }^{8}$ Mitchell (1996) argumenta ainda que se faz necessária a abordagem material e imaterial da paisagem para que possamos continuar pensando na morfologia da paisagem, que, não importa a forma em que seja representada, possui um papel nas relações e vida social. Finalmente, Mitchell (1996) conclui - ainda na dimensão reticente a utilização da metáfora paisagem-texto - que o significado é mais produzido do que refletido pela linguagem. Essa premissa nos permite assumir que as significações que a paisagem assume no plano individual são produzidas entre a linguagem e o mundo físico. Reside aqui a problemática de assumir a metáfora da paisagem-texto como uma predominância absoluta da linguagem em detrimento dos significados construídos também por intermédio das relações dos sujeitos com o mundo material. Para além da discussão acerca da razoabilidade da crítica de Mitchell, acreditamos que uma abordagem assertiva da paisagem passa pela incorporação de sua materialidade e imaterialidade, em algum ponto de equilíbrio entre a objetividade e

8 Particularmente apreciamos a abordagem de Don Mitchell. Contudo, ao se portar como um esmiuçador-mor das palavras pode recorrer ao vício de desviar o foco daquilo que está sendo centralmente discutido. 
subjetividade, o que não é o mesmo que defender uma visão pragmática e positivista da paisagem.

\section{Paisagem, literatura e historiografia}

A paisagem vista como um texto e, para além, a própria interpretação da paisagem realizada em forma de texto, nos levam a pensar sobre qual tipo de produção textual estamos nos referindo: um texto literário ou historiográfico? Estes limites são rígidos? Paulatinamente a geografia tem se posicionado mais próxima ao estudo da arte, do trabalho dos historiadores da arte e da literatura. O poeta, por exemplo, escreve sobre coisas que também são alvo de preocupação do geógrafo: as pessoas e o seu modo de viver em certos tempos e espaços (KIRMAN, 2007). Existe uma crença já consolidada de que o uso da poesia pode se tornar um interessante instrumento de aprendizado geográfico (KIRMAN, 2007; FOSTER, 2012). A proximidade entre a geografia e a arte é mal vista pelo positivismo pela perda da objetividade que é cara àqueles que somente veem ciência dentro de certos parâmetros. A superação destes limites não é um fato especialmente novo, visto que Alexandre von Humboldt transitou entre a literatura e a ciência, apresentando uma linguagem de rigor técnico, mas que repetidamente exprimia os sentimentos e as emoções do narrador (BRITO, 2015). Como uma mostra de que este entendimento acerca da utilidade da literatura não é tão recente, o encontro anual da AAG em 1974 teve uma sessão inteira foi devotada aos estudos da paisagem por intermédio da literatura (POCOCK, 1988). Com a ascensão da chamada nova geografia cultural, o sentido da paisagem, lugar e o uso a literatura surgem como formas alternativas e promissoras de pesquisa (AMORIM FILHO, 2008). ${ }^{9}$ A interface da geografia e literatura já é antiga, mas revigorou-se com 0 surgimento das abordagens humanistas na geografia (PORTEOUS, 1985). Apesar disto, Saunders (2010) considera que os estudos literários apoiam mais a união entre a geografia e a literatura do que a própria geografia o faz. A justificativa mais

9 A nova geografia cultural surge no contexto da crise da tradicional Geografia Cultural, quase concomitantemente ao movimento conhecido como "virada cultural". Foi apoiada na crítica à ideia lablachiana de gênero de vida. O rápido processo de urbanização e a intensificação do processo de globalização teriam colocado em xeque alguns dos pressupostos lablachianos (JACKSON, 1980; OAKES, 1997; AMORIM FILHO, 2008), que foram questionados, sobretudo, pelo pós-estruturalismo e pela pós-modernidade. Sivignon (2002) prefere especificar ao dizer que em nossas sociedades industrializadas e urbanizadas, as características culturais interveem pouco nas técnicas de produção, sendo esta a razão para a inadaptação da noção de gênero de vida. $O$ resgate da Geografia cultural com o novo rótulo se deu no contexto da profusão de correntes alternativas ao neopositivismo dos anos 1950, sendo passível de ser identificada, com robustez, nos anos 1980. 
comum para as ligações entre as duas disciplinas reside na percepção da literatura como um banco vívido de descrições sobre a paisagem e os modos de vida (MEINIG, 1983).

Para Bret Wallach (1997), todo trabalho de arte se constitui como uma forma de representar um fenômeno que se manifesta espacialmente a partir de escolhas pessoais do artista. Assim, Wallach se pergunta: "Todo trabalho de arte é uma construção. E toda descrição geográfica do mundo também não é?" (WALLACH, 1997, p.99). Silk (1984) acredita que um dos maiores benefícios do uso da literatura na interpretação geográfica (e o mesmo poderíamos falar sobre a pintura) é a negação das formas extremas da filosofia e metodologia positivista. Por sua vez, Deborah Hart (1986) prefere argumentar que "a geografia literária emergiu como uma jovem subdisciplina que usou a subjetividade do romancista, poeta, dramaturgo e autobiógrafo para complementar, dilatar a abordagem, desafiar e até mesmo corrigir o empiricismo do observador orientado quantitativamente" (HART, 1986, p.191).

As críticas sobre o uso das artes e da literatura apresentam-se na elusiva abstração sobre a materialidade e a imaterialidade. Formas objetivas e pretensamente "puras" cientificamente prezam pela materialidade absoluta, o que explica, no âmbito de suas formulações, o vilipêndio da subjetividade como ferramenta alternativa da análise geográfica. É importante considerar que a geografia e a literatura encontram-se tanto no mundo real quanto no mundo mental. "No mundo real, se encontram onde a descrição e a análise são compartilhadas entre geógrafos e escritores; no mundo mental, o encontro se dá no momento em que o entendimento sobre pessoas e lugares é buscado e a explicação sobre o seu relacionamento é almejado" (WATSON, 1983, p.386). John Fraser Hart (1982) salienta que a geografia é ao mesmo tempo tanto arte quanto ciência, pois o entendimento do sentido de uma área não pode ser reduzido ao processo formal de investigação científica. A resposta às encruzilhadas metodológicas envolvendo a combinação da objetividade e subjetividade não pode ser encontrada na opção pela materialidade extremada.

As grandes obras literárias e pictóricas deixam legados em múltiplas frentes. Participam da experiência do leitor/observador e, em alguma medida, impactam na sua concepção sobre certa porção do espaço e os indivíduos a ela atrelados (HUDSON, 1986). Certas paisagens podem ser valorizadas a partir de determinadas 
obras. O sertão e as veredas de Minas Gerais foram divulgadas por Guimarães Rosa, assim como as florestas da Europa Central foram construídas em meio a um misto de mistério, curiosidade e topofobia pelos irmãos Grimm. É interessante pensar que, para além do legado deixado pelos escritores e artistas, a terra natal de personalidades que amealharam sucesso acaba sendo valorizada, mesmo que não tenha sido tratada diretamente pelas suas obras. Este fenômeno parece ser mais intenso em pequenas localidades, que acabam despertando em algumas pessoas o interesse de visita, como se as experiências mais concretas estabelecidas com certas paisagens e lugares pudessem nos ajudar a compreender o brilhantismo de algumas mentes. Torna-se assim o desnudar da genialidade por intermédio da busca de reviver a experiência espacial do gênio, numa tentativa desprovida de fundamentos atrelados ao primado da razão. Parcela das visitas a Stratford-uponAvon e Itabira em parte se devem, respectivamente, à busca quase mística de compreensão da mente e quiçá do legado de William Shakespeare e Carlos Drummond de Andrade. É o espaço esgueirando-se entre o plano material e imaterial, naquele conceito platônico de chôra, resgatado por Augustin Berque (2004) nos estudos geográficos da paisagem.

É obsoleta a questão de saber se no discurso literário - tanto poético como romanesco - o autor como pessoa está ausente e o "eu" é um puro sujeito da enunciação (COMBE, 2010). "A gênese do conceito de "sujeito lírico" é, portanto, inseparável da questão das relações entre literatura e biografia e do problema da "referencialidade" da obra literária. O poeta lírico não se opõe tanto ao autor quanto ao autobiógrafo como sujeito da enunciação e do enunciado" (COMBE, 2010, p.120). Esta é uma questão similar a do pintor e de sua obra. Um protagonista criado em um romance, por mais que exiba características que representem a oposição aos valores do escritor, é dependente das experiências do seu criador intelectual. $O$ antagonismo dos valores somente será reconhecido pelo autor se o mesmo partir das bases dos seus próprios princípios e valores. Michel Collot preferiu uma abordagem menos determinante da questão, ao salientar que "quase nenhuma obra literária deixa de refletir, ainda que diretamente, as circunstâncias do lugar de existência do escritor" (COLLOT, 2012, p.22).

A crença de Collot acerca obra literária é também compartilhada por Hayden White (1988), no âmbito das historiografias. Já abordamos que a descrição da paisagem refere-se sempre a um tempo pretérito, dado o dinamismo que é o 
apanágio do espaço. Assim, convém nos referirmos a uma "historiografia da paisagem", que é um ponto central do raciocínio traçado neste artigo. White (1973) sacramenta que toda narrativa histórica tem um elemento de interpretação. White abordou outra face dos dilemas discursivos. Travando uma reflexão no âmbito da teoria da história, argumentou que os historiadores se veem, no ato da construção da narrativa, em um dilema que envolve a função analítica do discurso e as exigências das técnicas de storytelling, que acabam se constituindo como forças conflitantes.

White nos alerta que a acuidade dos detalhes da narrativa vai depender justamente do caminho escolhido para representar tanto o passado quanto o nosso pensamento sobre a sua importância histórica. O risco que se corre é que a busca obsessiva do épico e do espetacular pode resultar na negligência quanto às relevâncias analíticas em detrimento da construção de narrativas palatáveis e insinuantes, nas quais o apelo emocional oblitera a razão. White ainda acrescenta que há mais fatos do que a capacidade do historiador de incluí-los nas narrativas. ${ }^{10}$ $O$ fato do historiador se ver obrigado a escolher o que incluir e o que excluir na composição de sua narrativa revela a ação da interpretação, dentre muitas que seriam possíveis mediante o mesmo arsenal de documentos e informações disponíveis. Esta é uma das razões para a rejeição da tese do "olhar inocente" do historiador estabelecida por Leopold von Ranke (WHITE, 1973).

Talvez seja relevante considerar as sóbrias distinções entre o historiador e o historicista, realizadas pelo próprio White (1975) e por tantos outros. O historiador preocupa-se em elaborar pontos de vista, enquanto o historicista prefere construir teorias envolvendo os dados diacrônicos. Enquanto "o historiador estuda o passado em si mesmo, o historicista deseja utilizar o conhecimento sobre o passado para entender os problemas do presente ou, pior, para prever o caminho do desenvolvimento histórico futuro" (WHITE, 1975, p.48). Essa diferença entre o historiador e o historicista explica justamente as diferentes posições em relação ao entendimento da essência da narrativa histórica. Utilizar o conhecimento do passado para compreender o presente e quiçá predizer o futuro exigiria um método dentro dos cânones científicos. White (1973) mostra-se tão cético à isenção das narrativas

10 Neste aspecto concorda Lévi-Strauss (1989) em o Pensamento Selvagem: "o que é verdadeiro para a constituição do fato histórico não o é menos para sua seleção. Também desse ponto de vista, o historiador e o agente histórico escolhem, destacam e recortam, pois uma história verdadeiramente total os poria perante o caos" (LÉVI-STRAUSS, 1989, p.285). 
que compõem as historiografias quanto à própria possibilidade da história ser considerada ciência, debate a qual a geografia não escapou (SCHAEFER, 1953; HARTSHORNE, 1978; SACK, 1972 e 1974; SMITH, 1979; HARVEY, 1986; CAPEL, 2013).

Da mesma forma em que a discussão sobre as relações entre o autor e o sujeito da enunciação parece ser antiquada e superada, assim nos parece ser a discussão sobre a necessidade, tanto da história quanto da geografia - esta última na sua vertente próxima aos estudos das humanidades -, em se provar científica. ${ }^{11}$ Para as ciências humanas não parece prudente ignorar o papel da literatura nas estruturas discursivas. A força da literatura ajuda a explicar a constituição das modernas abordagens, seja como uma tentativa em rejeitar o viés literário - o que não acreditamos ser possível em uma dimensão intertextual de análise - ou para reivindicar os seus serviços como uma linha auxiliar da reflexão. Como vimos, a historiografia também sofre com o ceticismo alheio, à medida que a abordagem de Hayden White $(1973 ; 1975 ; 1981 ; 1984 ; 1988)$ nos revela um dilema que aflige 0 relato histórico similar à de um texto de literatura: a incapacidade de apartar o autor do "eu" da enunciação.

Há de se considerar outra dimensão que une a narrativa histórica e a interpretação da paisagem: tanto os textos literários quanto historiográficos não podem ser entendidos como completamente autorais. Os textos são construções intertextuais, compreensíveis somente nos termos de outros textos (CULLER, 1976). A intertextualidade, que é um dos termos mais utilizados no vocabulário crítico contemporâneo (ALLEN, 2000), "enfatiza que ler é colocar um trabalho em um espaço discursivo, relacionando-o a outros textos e códigos desse espaço. Escrever também é uma atividade similar: é assumir uma posição em um espaço discursivo" (CULLER, 1976, p.1383). Em uma abordagem e título provocativos, Paul Olsson (1983) publicou o manifesto intertextual Expressed Impressions of Impressed Expressions. O autor nos aponta que um texto é uma textura de palavras. Para ele, nenhuma palavra é uma nova palavra, pois são oriundas de outros textos e contextos. Assim, todas as expressões carregam múltiplas imagens: aquilo que é

11 Para Hayden White (1973), a busca pelas generalizações apresentava-se importante pelo fato de providenciar a panglossiana busca pelas leis, que dariam autoridade científica à história. Ou seja, as generalizações obliteram a diversidade, fazendo com que a busca de leis por este caminho seja falsa. White alerta, em um endosso à Nietzsche, que as generalizações podem fazer com que o trabalho do historiador seja inútil. Isto se explica porque o resíduo da verdade que é contida na generalização, após a remoção da parte obscura e insolúvel, nada mais é do que o mais comum dos conhecimentos. 
lembrado, desmembrado e, às vezes, apagado. No seu apego a intertextualidade e à desconstrução, o autor ainda provoca: "cidades são metáforas e teorias das cidades são metáforas das metáforas", concluído a posteriori que "teorias são metáforas de metáforas" (OLSSON, 1983, p.61-63).

É plausível considerar que a paisagem pode se enquadrar como um texto que possui interface com outros textos. Há três planos de justificativa para compreendermos a intertextualidade da paisagem:

- Plano da intertextualidade literal: a expressão da paisagem por meio da linguagem apresenta interface com outros textos, não só sobre a paisagem descrita ou genericamente sobre paisagens, mas sobre qualquer abordagem;

- Plano da intertextualidade metafórica: a paisagem pode ser vista como um texto a ser lido; sua expressão é um texto produzido. Neste plano, como nos lembra Halbwachs (1990), a interpretação da paisagem é guiada diacronicamente pela experiência humana, moldada pela memória individual e coletiva. A intertextualidade se manifesta, na dimensão metafórica, por intermédio da dependência das identidades (e do conjunto de valores e preferências carregados pelo indivíduo) frente à vida em sociedade. Ainda que desacreditemos no determinismo de uma superestrutura social capaz de criar uma massa monolítica de sujeitos, é inegável a força da influência da vida em sociedade na composição identitária. Assim, da mesma forma que textos são compreendidos por outros textos, a paisagem é individualmente percebida e expressa (ações que não são completamente congruentes) pela força da influência das experiências sociais

- Plano na intertextualidade espaço-temporal: é plausível considerar que a paisagem percebida em um plano material e mesmo imaterial não se explica enquanto fotografia: são necessários o entendimento de processos além de sua escala de análise para a sua compreensão e eventos ocorridos em tempos idos que somente deixaram suas cicatrizes. Nessa metáfora, salientamos que a intertextualidade paisagística nos leva a crer que uma explicação mais aprofundada sobre o espaço observado envolve 0 conhecimento de outro lugar e de outro tempo, como textos nem sempre acessíveis aos intérpretes. 
A literatura e a historiografia são, inter alia, formas dominantes de descrição paisagística. As problematizações realizadas até o presente momento do texto pertencem ao âmbito do fazer geográfico, ainda que entremos nos domínios interdisciplinares. Os dilemas aqui descritos que recaem sobre a literatura e a historiografia são, deste modo, dilemas paisagísticos e, portanto, geográficos.

\section{Paisagem e historiofotia}

Hayden White argumenta que as imagens são mais adequadas do que textos para a representação de certos fenômenos, como a paisagem, guerras e as emoções humanas. Acrescenta ainda que os elementos visuais são um complemento e não um suplemento da narrativa histórica, sendo que algumas informações sobre o passado são podem ser providas por intermédio de recursos visuais (WHITE, 1988). Apesar disso, White tece uma crítica: "estamos inclinados a usar as figuras primariamente como ilustrações do nosso discurso textual. Nós não temos o hábito de explorar todas as possibilidades do uso da imagem como principal meio discursivo" (WHITE, 1988, p.1194). Para fortalecer o papel das imagens na interpretação, White ainda argumenta que a historiografia é muito mais apurada nos períodos que desfrutam do advento da fotografia e do cinema. Todavia, para a representação da paisagem e do lugar, há de se considerar a força da pintura como fonte interpretativa, à medida que ela nos revela elementos acerca do artista, do tempo e do espaço representado. As pinturas - e este livro está repleto delas - não podem ser encaradas como um elemento totalizante da interpretação, portador de uma verdade histórica e do fato cabal da historiografia da paisagem. Muir (1998) salienta que a paisagem, do ponto de vista estético, é uma combinação entre arte, artefato e natureza, o que justifica a interface arte-paisagem. Donald Meinig destacou que na Syracuse University, assim como em muitas universidades dos Estados Unidos, o departamento de geografia se insere no colégio de artes e ciências, destacando o quanto que as expressões artísticas são importantes para o fazer geográfico (MEINIG, 1983).

A despeito de suas limitações quanto à cobertura espacial (enquadramento) e acuidade na representação (REES, 1973), a pintura se enquadra como uma potencial ferramenta para o eclético profissional que é o geógrafo. Apesar da existência de pinturas rupestres, que são identificadas mesmo em áreas sem iluminação natural de cavernas (TRAVASSOS; RODRIGUES; MOTTA, 2012), não 
existem pinturas muito antigas. A diminuição do número de pinturas é exponencial em cada século anterior ao vitoriano. Pinturas representam também as emoções humanas e podem aludir à tentativa do artista de transmitir dogmas. Por isso, interpretações literais podem ser problemáticas. Pinturas antigas representavam o gado em dimensões bem menores do que o homem, o que se tratava de uma tentativa do artista de hierarquizar as coisas vivas (REES, 1973). As mudanças na percepção da relação entre o homem e a natureza repercutiram também nas formas de representação da pintura, assim como as diferenças de estilo, técnicas e mudança nos contextos sociais, dentre as quais as de ordem religiosa.

Na primeira metade do século XIX, o Oeste americano foi romantizado pelas abordagens de um grupo expressivo de pintores. Em uma reação clara ao racionalismo que marcou profundamente a era do lluminismo, os pintores eram influenciados pelo Romantismo, que não eram necessariamente guiados pela ciência, mas pelas emoções (ALLEN, 1992). Temas como a pastorícia e o apelo pelas descrições etnográficas que até descreviam o mundo mágico do ritualismo indígena eram frequentes na pintura deste tempo. Alfred Jacob Miller foi um dos artistas que marcaram este período romântico de idealização do Oeste americano. Em meio a temas pastorícios, destacava a nobreza do indígena, que seria uma característica marcante inata e se constituía como uma expectativa de comportamento social "anterior ao contato expressivo com o homem branco, que poderia fazer com que o indígena adquirisse os seus sórdidos hábitos" (ALLEN, 1992, p.32). Essa visão é uma antítese da imagem bárbara e selvagem muito relatada à época da aurora colonial do continente americano.

A visão romântica do oeste americano se estende ao quadro físico, não sendo rara a representação da paisagem como um éden verdejante, como na tela Fort Pierre de George Catlin. Essas representações imagéticas ajudam a consolidar o Oeste magnífico, como se a paisagem se oferecesse à colonização. A invenção da tradição romântica na descrição do Oeste americano ainda vive em diferentes instâncias do imaginário comum e "os esforços dos revisionistas históricos de mostrar o Oeste como ele realmente era tem tido relativamente pouco efeito sobre a contínua aceitação da tradição romântica entre o público americano" (ALLEN, 1992, p.39). A visão média do americano passou a incluir, com a ascensão posterior da indústria cinematográfica e da consolidação do gênero Western, a figura do herói 
destemido, como diversas vezes foi protagonizado por John Wayne (BARBOSA, 1998).

Figura 1- Alfred Jacob Miller. The Trapper's bride (1846-47)

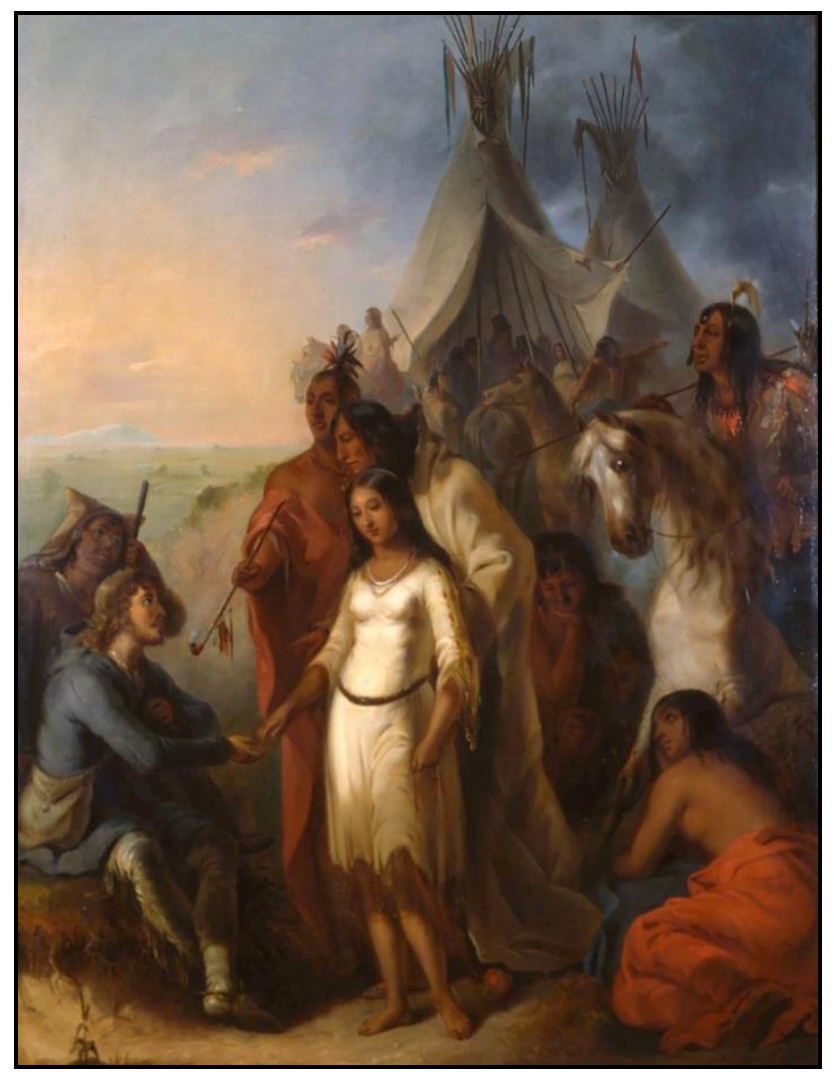

Óleo sobre tela, $91,4 \times 71,1 \mathrm{~cm}$, Eiteljorg Museum of American Indians and Western Art, Indianapolis, Indiana. A visão romântica e idealizada do nobre selvagem traziam no imaginário a pureza não somente da mulher indígena, mas de todos os índios do oeste americano.

https://en.wikipedia.org/wiki/File:The_Trapper\%27s_Bride.jpg

A historiofotia contém uma narrativa. Para White (1984), a narrativa é um modo de discurso, uma maneira de comunicar e, também, um produto confeccionado pela adoção de um modo de discurso. Rechaçando a dicotomia entre a presença do "verdadeiro" e "falso" nas narrativas, o autor sugere que as divergências sejam expressas em outra oposição: real versus imaginário. A partir desta elaboração, White nos pergunta: "Não é possível que a questão da narrativa em qualquer discussão de teoria histórica é sempre em seu desfecho a respeito da função da imaginação na produção de uma específica verdade humana?" (WHITE, 1984, p.33). Justamente pelas problematizações que envolvem a comunicação e o autor, não vemos diferenças significativas na legitimidade discursiva entre historiografias e historiofotias. 
Figura 2- George Catlin, Fort Pierre (1832)

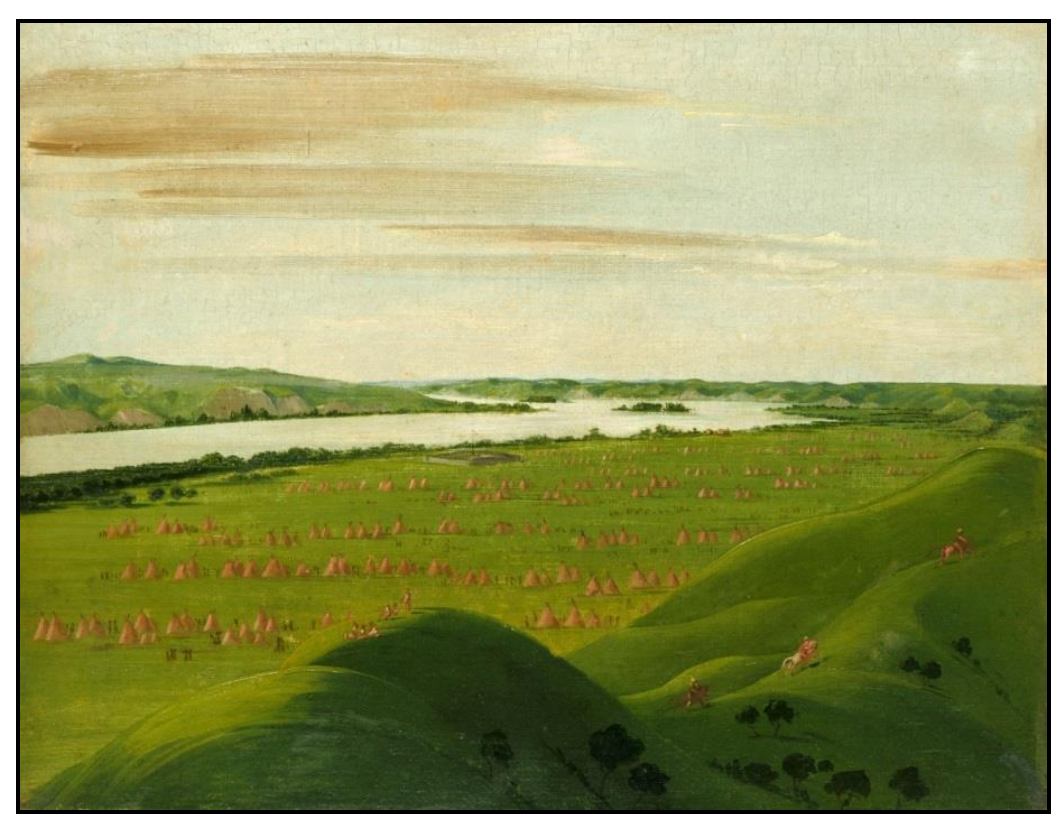

Óleo em tela, $28.5 \times 36.8 \mathrm{~cm}$, Smithsonian Art Museum. A representação do Oeste americano na primeira metade do século XIX como férteis planícies propícias à colonização são muito comuns. https://americanart.si.edu/artwork/fort-pierre-mouth-teton-river-1200-miles-above-saint-louis-4062

White destaca ainda que o senso moral que é trazido pela representação dos eventos públicos pretéritos difere do trazido pelas memórias pessoais. A razão pela qual as narrativas de memórias pessoais nos contam muito pouco sobre a concepção da história é que elas são repletas de crenças morais pessoais. Nesse sentido, os eventos públicos, em uma moderna historiografia, podem utilizar do processo de intermediação de narrativas, que acabam lidando com os distintos valores que amparam o discurso. Hayden White (1988) alerta que alguns suportes que buscam revelar o pretérito são problemáticos nesse sentido: analisando as historiofotias, o autor diz que filmes não conseguem em geral fazer essa intermediação, trazendo histórias lineares que são, em sua essência, simples interpretações desprovida do choque de pontos de vista.

\section{Considerações Finais}

Dado o dinamismo inexorável e à passagem implacável do tempo atomístico, descrever a paisagem e ler descrições sobre a paisagem são sempre atos que nos remetem a um tempo que já se foi. Por isso mesmo, este artigo, para além das considerações teóricas aqui realizadas, é um convite ao aprofundamento da pesquisa e apropriação epistemológica da teoria da história, que abriga, por sua vez, 
uma discussão madura - ainda que não consensual - sobre as formas de se abordar o passado. Com a ascensão da nova geografia cultural e a disseminação do uso da metáfora da paisagem como um texto, escancarou-se a necessidade de uma abordagem interdisciplinar na análise paisagística.

White argumenta que a noção sobre um evento é tão ambígua ao ponto de não fazer sentido falar em um evento per se, mas somente sobre eventos sob uma descrição. Nesse sentido, destaca a diferença entre eventos e fatos: "eventos acontecem; fatos são constituídos pela subsunção de eventos que estão sob uma descrição" (WHITE, 1988, p.1196). O autor destaca que as histórias contadas nas narrativas são uma mimese das histórias vividas em alguma fatia da realidade histórica. É de se destacar que dentro da própria história existem correntes diferentes que veem as narrativas de forma distinta, chegando ao ponto de alguns estudiosos da linguagem a verem apenas como um meio transmissor da mensagem, dotada do mesmo valor de uma equação matemática ou do código morse (WHITE, 1984).

Qual seria de fato o constrangimento acerca da existência do desajuste entre ideias e comunicação? O desejo de congruência absoluta entre o que é pensado e o que é comunicado se assemelha a busca panglossiana pela verdade. A historiografia e a historiofotia enriquecem a disposição de narrativas paisagísticas que servem para que possamos intermediar a realidade. Por mais que a pretensão de dimensionamento da realidade seja absurda em uma teoria baseada nas subjetividades, a pluralidade de narrativas nos possibilita o confronto de ideias, 0 exercício da alteridade e a prática do relativismo, tão caros aos estudos culturais. Reside neste ponto a relevância da literatura e das artes na pesquisa paisagística, acima de eventuais constrangimentos. Esta discussão não é fácil de ser assimilada por aqueles que tratam a cultura de maneira reificada, como se fosse passível de descrição e ocupasse espaços onde pudesse se dispor como um tecido homogêneo, lógica rechaçada por tantos autores (HALL, 2006; 2013; SAÏD, 2007; 2011; BHABHA, 2013; SILVA; COSTA, 2018A; 2018B; 2020). Nessa lógica, indivíduos tornam-se meros replicadores miniaturizados da entidade social e cultural que os abriga (COHEN, 1993), contexto marcado pelo esvaziamento do valor das identidades. O mais sensato é confiar na força das identidades, as quais - mesmo repousando no leito de certas estruturas sociais - fazem valer as diferenças de valores e visões de mundo (ainda que possamos dizer que algumas dessas 
diferenças possam se apresentar sutis). Essa é a mesma consideração que podemos propor àqueles que acreditam na força das metanarrativas, que se apresentam como aniquiladoras de discursos alternativos e opositora das intermediações discursivas. É na diversidade das historiografias e historiofotias e no seu processo de intermediação que se localiza a abordagem assertiva da paisagem.

\section{REFERÊNCIAS}

ALLEN, Graham. Intertextuality: the new critical idiom. London and New York: Routledge, 2000.

ALLEN, John Logan. "Horizons of the sublime: the invention of the romantic West". Journal of Historical Geography, v.18, n.1, pp.27-40, 1992.

AMORIM FILHO, Oswaldo Bueno. "Literaturas de explorações e aventuras: As "viagens extraordinárias" de Júlio Verne". Sociedade e Natureza, v.20, n.2, dezembro, pp.107-119, 2008.

ANTROP, Marc. "Why landscapes of the past are important for the future". Landscape and urban planning, n.70, pp.21-34, 2005.

BARBOSA, Jorge Luiz. "Paisagens Americanas: Imagens e Representação do Wilderness". Espaço e Cultura, UERJ, n.5, pp.1-14, 1998.

BARNES, Trevor J; DUNCAN, James S. Writing Worlds: Discourse, Text and Metaphor in the Representation of Landscape. London and New York: Routledge, 1992.

BENDER, Barbara. "Time and landscape". Current Anthropology, v.43, supplement, augoct, pp.103-112, 2002.

BERQUE, Augustin. "Beyond the modern landscape". Architectural Association school of Architecture, n.25, summer, pp.33-37, 1993.

BERQUE, Augustin. "Offspring of Watsuji's theory of mileu (Fûdo)". Geojournal, n.60, p.389-396, 2004.

BERQUE, Augustin. "Geogramas, por uma ontologia dos fatos geográficos". Geograficidade, v.2, n.1, verão, pp.4-12, 2012.

BERQUE, Augustin. “A cosmofania das realidades geográficas”. Geograficidade, v.7, n.2, inverno, pp.4-16, 2017.

BHABHA, Homi K. O local da cultura. Belo Horizonte: editora UFMG, 2013.

BRITO, Thiago. "Humboldt entre a filosofia da natureza e a ciência moderna". Revista Sociedade e Natureza, v.27, n.2, pp.195-208, 2015.

BURGESS, Rod. "The concept of nature in Geography and Marxism". Antipode, v.10, n.2, pp.1-11, 1978.

BURGESS, Jacquelin. “Editorial”. Landscape Research, v.21, n.1, pp.5-12, 1996. 
CAPEL, Horácio. "Neopositivismo e Geografia Quantitativa". (in): CAPEL, Horacio. Ruptura e continuidade no pensamento geográfico. Maringá: EDUEM, 2013.

CARVALHO, José Luiz de. "Denis Cosgrove e o desenvolvimento da perspectiva simbólica e iconográfica da paisagem”. Geograficidade, v.7, n.2, pp.87-97, 2017.

COHEN, Anthony P. "Culture as identity: An Anthropologist's view". New Literary History, v.24, pp.195-209., 1993.

COLLOT, Michel. "Rumo a uma geografia literária". Gragoatá, n.33, 2ํsemestre, pp.17-31, 2012.

COMBE, Dominique. "A referência desdobrada: o sujeito lírico entre a ficção e a autobiografia". Revista USP, n.84, dezembro-fevereiro, pp.112-128, 2010.

CORRÊA, Roberto Lobato. "Denis Cosgrove - a paisagem e as imagens". Espaço e Cultura, n.29, pp.7-21, 2011.

COSGROVE, Denis. "Prospect, Perspective and the Evolution of the Landscape Idea". Transactions of the Institute of British Geographers, new Series, v.10, n.1, pp.45-62, 1985.

COSGROVE, Denis; JACKSON, Peter. "New Directions in Cultural Geography". Area, vol.19, n.2, jun, pp.95-101, 1987.

CULLER, Jonathan. "Presupposition and Intertextuality". Comparative Literature, v.91, n.6, december, pp.1380-1396, 1976.

DEMERITT, David. "The nature of metaphors in cultural geography and environmental history". Progress in Human Geography, v.18, i.2, pp.163-185, 1994.

DEMERITT, David. "What is the "social construction of nature? A tipology and sympathetic critique". Progress in Human Geography, v.26, i.6, pp.767-790, 2002.

DUNCAN, James; DUNCAN, Nancy. "(Re)reading the landscape". Environmental and Planning D. Society and Space. v.6, pp.117-126, 1988.

DUNCAN, James. The city as a text:.The Politics of Landscape Interpretation in the Kandya Kingdom. Cambridge: Cambridge University Press, 1990.

DUNCAN, James. “Landscape Geography, 1993-1994”. Progress in Human Geography, v.19, n.3, pp.414-422, 1995.

FOSTER, Ellen J. "Finding Geography Using Found Poetry". The Geography Teacher, v.9, n.1, pp.26-29, 2012.

FRIEDMAN, Jonathan. "Our time, their time, world time: The transformation of temporal modes". Ethnos: Journal of Anthropology, v.50. n.3-4, pp.168-183, 1985.

HALBWACHS, Maurice. A Memória Coletiva. São Paulo: Editora Vértice, 1990.

HALL, Stuart. A identidade cultural na pós-modernidade. Rio de Janeiro: DP\&A, 2006. 
HALL, Stuart. "Pensando a diáspora: reflexões sobre a terra no exterior" (in): HALL, Stuart Sovik, Liv (org.). Da diáspora: identidades e mediações culturais. Belo Horizonte: Ed.UFMG, 2013.

HART, Deborah. "A Literary Geography of Soweto". Geojournal, v.12, n.2, pp.191-195, 1986.

HART, John Fraser. "Highest form of the Geographer's Art". Annals of the Association of American Geographers, v.72, i.1, march, pp. 1-29, 1982.

HARTSHORNE, Richard. Propósitos e natureza da Geografia. São Paulo: Hucitec Edusp, 1978.

HARVEY, David. Explanation in Geography. Bristol: Edward Arnold, 1986.

HARVEY, David. Condição Pós-Moderna. São Paulo: Edições Loyola, 2004.

HUDSON, Brian J. "Landscape as Resource for National Development: a Caribbean View". Geography, v.71, n.2, april, pp.116-121, 1986.

INGOLD, Tim. "The temporality of the landscape". World Archaelogy, v.25, n.2, pp.152-174, 1993.

JACKSON, Peter. “A Plea for Cultural Geography”. Area, v.12, n.2, pp.110-113, 1980.

KIRMAN, Joseph M. "Aesthetics in Geography: Ideas for Teaching Geography Using Poetry". Journal of Geography, v.106, n.5, pp.207-214, 2007.

KIYOTANI, Ilana. "O conceito de paisagem no tempo". Florianópolis: Geosul, V.29, n.57, pp.27-42, 2014.

LARSEN, Svend Erik. "Is nature really natural?" Landscape Research, v.17, n.3, pp.116122, 1992.

LÉVI-STRAUSS, Claude. O pensamento selvagem. Campinas, Papirus, 1989.

MARANDOLA, Hugo Leonardo; OLIVEIRA, Lívia de. "Origens da paisagem em Augustin Berque: pensamento paisageiro e pensamento da paisagem". Geograficidade, v.8, n.2, pp.139-148, 2018.

MASSEY, Doreen. "Landscape as provocation". Journal of Material Culture, v.11, n.1, pp.33-48, 2006.

MAXIMIANO, Liz Abad. "Considerações sobre o conceito de paisagem". RA 'E GA, n.8, pp.83-91, 2004.

MEINIG, Donald W. "Geography as an art". Transactions of the Institute of British Geographers, new Series, v.8, n.3, pp.314-328, 1983.

MEREDITH, T. "The upper Columbia valley, 1900-1920: an assessment of "boosterism" and the "biography of landscape". Canadian Geographer, n.29, pp.44-55, 1985.

MIKESELL, Marvin W. "Tradition and innovation in cultural geography". Annals of the Association of American Geographers, v.68, n.1, march, pp.1-16, 1978. 
MITCHELL, Don. "Book review of Writing Worlds". Professional Geographer, v.45, i.4, pp.474-475, 1993.

MITCHELL, Don. "Sticks and Stones: The Work of landscape (A Reply to Judy Walton's "How real(ist) Can You Get?")". Professional Geographer, v.48, n.1, pp.94-96, 1996.

MUEHRCKE, Philip C; MUEHRCKE, Juliana O. "Maps in literature". Geographical Review, v.64, n.3, jul., pp.317-338, 1974.

MUIR, Richard. “Landscape: a wasted legacy”. Area, v.30, n.3, pp.263-271, 1998.

MUNN, Nancy D. "The cultural anthropology of time: a critical essay". Annual Review of Anthropology, v.21, pp.93-123, 1992.

NAME, Leo. "O conceito de paisagem na geografia e sua relação com o conceito de cultura". Geotextos, v.6, n.2, dez., pp.163-186, 2010.

OAKES, Timothy. "Place and the Paradox of Modernity". Annals of the Association of American Geographers, v.87, n.3, pp.509-531, 1997.

OHNUKI-TIERNEY, Emiko. "Concepts of Time among the Ainu of the Northwest Coast of Sakhalin”. American Anthropologist, v.71, n.3, pp.488-492, 1969.

OLIVEIRA, Lívia. "Percepção da paisagem geográfica: Piaget, Gibson e Tuan". Geografia, v.25, n.2, pp.5-22, 2000.

OLSSON, Paul Gunnar. "Expressed Impressions of Impressed Expressions”. Geographical Analysis, vol.5, n.1, January, pp.60-64, 1983.

OLWIG, Kenneth R. "Has "geography" always been modern?: choros, (non)representation, performance, and the landscape". Environmental and Planning A, v.40, pp.1843-1861, 2008.

PEDROSA, Breno Viotto. "O império da representação: a virada cultural e a geografia".

Espaço e Cultura, n.39, jan./jun, pp.31-58, 2016.

POCOCK, Douglas C. D. "Geography and Literature". Progress in Human Geography, v.12, Issue 1, march, pp.87-102, 1988.

PORTEOUS, J. Douglas. "Smellscape". Progress in Human Geography, v.9, i.3, pp.356378, 1985.

RAFFESTIN, Claude. "Paysage et territorialité". Cahiers de geographie du Quebec, v.21, n.53-54, pp.123-134, 1977.

REES, Ronald. "Geography and landscape painting: an introduction to a neglected field". Scottish geographical Magazine, v.89, n.3, December, pp.147-157, 1973.

ROWNTREE, Lester. "Cultural/humanistic geography". Progress in Human Geography, v.10, n.4, pp.580-586, 1986.

ROWNTREE, Lester. "Orthodoxy and new directions: cultural/humanistic geography". Progress in Human Geography, v.12, n.4, pp.575-586, 1988.

SANTOS, Milton. A Natureza do Espaço. São Paulo: Edusp, 2012. 
SACK, Robert David. "Geography, Geometry and Explanation". Annals of the Association of American Geographers, v.62, i.1, pp.61-78, 1972.

SACK, Robert David. "Chorology and Spatial Analysis". Annals of the Association of American Geographers, v.64, i.3, september, pp.439-452, 1974.

SAÏD, Edward. Orientalismo. São Paulo: Companhia de Bolso, 2007.

SAÏD, Edward. Cultura e Imperialismo. São Paulo: Companhia de Bolso, 2011.

SAUNDERS, Angharad. "Literary geography: reforging the connections". Progress in Human geography, v.34, i.4, pp.436-452, 2010.

SCHAEFER, Fred K. "Excepcionalism in Geography: A methodological examination". Annals of the association of American geographers, v.43, n.3, pp.226-249, 1953.

SCHEIN, Richard H. "The Place of landscape: A Conceptual Framework for interpreting an American Scene". Annals of the Association of American Geographers, v.87, n.4, pp.660-680, 1997.

SILK, J. "Beyond Geography and Literature". Environmental and Planning D: Society and Space, v.2, pp.151-178, 1984.

SILVA, Leonardo Luiz Silveira da; Costa, Alfredo. "A inadequação das regionalizações culturais mediante os pressupostos do pós-colonialismo". Salvador: Geotextos, v.14, n.1, pp.225-247, 2018a.

SILVA, Leonardo Luiz Silveira da Silva; Costa, Alfredo. "Cultura como comunidade imaginada: uma crítica à abordagem ontológica da cultura nos estudos geográficos". Geografias, v.16, n.1, pp.27-41, 2018b.

SILVA, Leonardo Luiz Silveira da Silva; Costa, Alfredo. "Questionando as delimitações cartográficas da cultura”. Caminhos de Geografia, v.21, n.73, pp.445-457, 2020.

SIVIGNON, Michel. "Sobre a Geografia Cultural”. Espaço e Cultura, n.14, jul-dez, pp.33-39, 2002.

SMITH, Neil. "Geography, Science and post-positivist modes of explanation". Progress in Human Geography, v.3, i.3, pp.356-383, 1979.

TRAVASSOS, Luiz Eduardo Panisset; RODRIGUES, Bruno Durão; MOTTA, Aécio Rodrigo Schwertz da. "Caverna das mãos: an example of dark zone rock art in Brazil". Acta Carstologica, v.41, n.2-3, pp.304-309, 2012.

VALENTINE, Gill. "Whatever happened to the social? Reflections on the "cultural turn" in British Human Geography”. Norwegian Journal of Geography, v.55, pp.166-172, 2001.

VIRILIO, Paul. Speed and Politics. Los Angeles: MIT Press, 2007.

WALLACH, Bret. "Painting, Art History, and Geography". Geographical Review, v.87, n.1, January, pp.92-99, 1997.

WALTON, Judy R. "How Real(ist) can you get?" Professional Geographer, v.47, i.1, pp.6165, 1995. 
WATSON, James Wreford. "The soul of geography". Transactions of British Geographers, v.8, n.4, pp.385-399, 1983.

WHITE, Hayden. "Interpretation in History". New Literary History, v.4, n.2, winter, pp.281314, 1973.

WHITE, Hayden. "Historicism, History, and the Figurative Imagination". History and Theory, December, v.14, n.4, pp.48-67, 1975.

WHITE, Hayden. "The narrativization of Real Events". Critical Inquiry, v.7, n.4, summer, pp.793-798, 1981.

WHITE, Hayden. "The Question of Narrative in Contemporary Historical Theory". History and Theory, v.23, n.1, February, pp.1-33, 1984.

WHITE, Hayden. "Historiography and Historiophoty". The American Historical Review, v.93, n.5, December, pp.1193-1199, 1988.

\section{NOTAS DE AUTOR}

\section{CONTRIBUIÇÃO DE AUTORIA}

Leonardo Luiz Silveira da Silva - Concepção e reflexão epistemológica; Revisão bibliográfica; Elaboração do manuscrito, revisão e aprovação da versão final do trabalho.

\section{FINANCIAMENTO}

Não se aplica.

\section{CONSENTIMENTO DE USO DE IMAGEM}

Não se aplica.

APROVAÇÃO DE COMITÊ DE ÉTICA EM PESQUISA

Não se aplica.

\section{CONFLITO DE INTERESSES}

Sem conflitos.

\section{LICENÇA DE USO}

Este artigo está licenciado sob a Licença Creative Commons CC-BY. Com essa licença você pode compartilhar, adaptar, criar para qualquer fim, desde que atribua a autoria da obra.

\section{HISTÓRICO}

Recebido em: 24-09-2020

Aprovado em: 03-07-2021 